\title{
The Impact of Applying Computer-Based Training Strategy upon Developing the Skill of Solving Mathematical Word Problem among Students with Learning Disabilities
}

\author{
Burhan M. Hamadneh (Corresponding author) \\ Assist. Professor of Special Education, College of Education, Najran University \\ Najran, Saudi Arabia
}

Hassan A. Hamad

Assist. Professor of Special Education, Deanship of Community Service, Najran University

Najran, Saudi Arabia

Mamoun M. Al-azzam

Lecturer in Computer Science, Community College, Najran University

Najran, Saudi Arabia

Received: February 14, 2016 Accepted: February 29, 2016 Published: March 28, 2016

doi:10.5296/ire.v4i1.9023 URL: http://dx.doi.org/10.5296/ire.v4i1.9023

The paper is funded by the Deanship of Scientific Research, Najran University (NU/SHED/14/025)

\begin{abstract}
The present study aimed to investigate the impact of applying a computerized strategy based on training upon developing the skill of Math word problem solving among students with learning disabilities (attention-deficit) in Mathematics. The study sample consisted of (14) students with learning disabilities in Mathematics, randomly chosen from elementary public
\end{abstract}


schools in the city of Najran, Saudi Arabia, and distributed evenly into two groups: The control group (7) students who studied in the traditional way and the experimental group (7) students who studied in computer-based training strategy. Pre-and-post achievement test conducted in Mathematics. The results showed that there are statistically significant differences at the post-achievement test in mathematics in the skill of Math word problem solving in favor of members of the experimental group, which indicates the effectiveness of the computer-based training strategy upon developing the skill of Math word problem solving. Accordingly, the study made several recommendations; the most notably is urging official bodies and educational institutions to provide educational computerized software and to be circulated to elementary public education schools.

Keywords: computerized strategy, math word problem, students with learning disabilities

\section{Introduction}

Rapid development in teaching and learning strategies occurred in the $20^{\text {th }}$ century; hence, it has become difficult to expect the individual's performance in the future. So, the total objectives of education have been directed to develop the ability to solve problems, which is the most important capability that should be reinforced among students to help them adapt and cope with various problems in the rapidly-changing life.

Utilizing of computer capabilities and benefiting from them is an apparent feature of the present era because of the benefits that emerged from life styles. We should adapt to these rapid changes in our societies that will build comprehensive and integrated policies and cultures in order to ensure getting rid of the traditional pattern in the daily and professional life and reinforce the scientific, analytical, and experimental methodology as a way to solve problems and various issues; where the scientific and technological progress is closely related to computer systems and software. So, the official educational institutions are required to do their best to cope with such growing challenge for which concerted efforts are required to technologically qualify our children for making them capable of adaptation and competition (Sobh and Ajlouni, 2003).

In this connection, Ray (2002) indicated that students have positive attitudes towards learning by modern strategies, which differ from traditional strategies, such as using the Internet, elearning and computer software. Anil (2002), Kara (2009) and Dinder (2008) confirmed that it is needed to design new strategies in learning Mathematics that contribute to the acquisition of skills necessary to solve Math word problems among students of learning disabilities (attention-deficit).

The emergence of software techniques entitled us to apply them easily in all professional areas of life, especially in education and learning. In this regard, Al-sabagh (2005) pointed out that Mathematics based on the inductive method to get mathematical knowledge included some scientific skills such as drawing, measurement, and solving math word problems. Math requires particular arrangement to provide the subject matters. It helps the students develop their thoughts to make them able to take decisions and make solutions appropriate to confront 
the problems and attitudes in daily and future life; so it is necessary to use modern scientific methods that contribute to improve math learning, such as computer and software techniques.

Nunes and Moreno (2005) assured that educational technology has been recently utilized in all educational trends, as the computer played a major role in teaching all courses and at all various levels of education. Therefore, the current study seeks to convey the significance of utilizing a computerized strategy based on training in Mathematics; because of its impact on improving the level of students with learning disabilities (attention-deficit) in solving Math word problem.

A number of Arab and foreign studies confirmed the obvious impact of using the computer upon the academic achievement of the students, where Abu-Raiya (1993) pointed in his study to the use of computerized learning-by-playing strategy in the acquisition of skills of the four arithmetic operations among students of the elementary sixth grade in private schools of Amman, Jordan. The results showed that there were statistically significant differences in the academic achievement of participants in the four arithmetic skills due to the computerized learning-by-playing strategy. Shashanni (1995) and Kirkpatrik \& Caban (1998) confirmed that the study of Mathematics through the computerized software has a positive impact on student achievement in Mathematics. Martindale, Pearson and Curda (2005) showed that there is an impact of the use of educational software in Mathematics upon improving the fifth grade students' performance in Math and the statistical differences were in favor of the experimental group. Al-Maliki (2008) showed that there is an effect of utilizing the enriching activities by a computer program in the treatment of learning disabilities in Mathematics among a sample of third grade students with learning disabilities and the differences were in favor of the experimental group. Bcal and qu, lee (2008) confirmed that the computer software contributes to the development of motivation and achievement in Mathematics among students. Dinder (2008) also confirmed that the use of computer educational software contributed to increasing the student achievement of Mathematics in the elementary stage. Kara (2009) assured that the use of educational computer software contributed to the development of achievement for students in improving their attitudes towards Science and Mathematics. The study of Jeanine, et al. (2012), conducted in the southwestern of America, showed that there is an impact of the use of educational computer activities over the Internet upon improving academic achievement among students with learning disabilities in Mathematics.

Reviewing the pieces of literature mentioned above supports conducting the current study and achieving its objectives because Saudi Arabia lacks such studies to detect the effectiveness of applying computerized strategy for the acquisition of skills of solving Math word problems among students with learning disabilities (attention-deficit) in Mathematics in elementary schools.

\section{Statement of the Problem}

The studies conducted on Mathematics pointed that the students are low-achievers in the skill of solving mathematical problems and showed that there is a need to design new strategies in teaching of Mathematics that contribute to the acquisition of skills necessary to solve Math 
word problems - these results shown in Hall (2002), Marge (2002), the study of Ersan \& AbuZeina (2005) and the study of Al-Maliki (2008).

Therefore, the study sought to detect the effectiveness of a computer-based training strategy to develop skills of solving Math word problem among students with learning disabilities (attention-deficit) in Mathematics. Thereby, the study tried to answer the following two questions:

1. Are there statistically significant differences at the level of $(a=0.05)$ between the control group and the experimental group on the pre-test of skill of solving Math word problem?

2. Are there statistically significant differences at the level of $(a=0.05)$ between the control group and the experimental group on the post-test of skill of solving Math word problem?

\subsection{The Significance of the Study}

- The results of this study draws the attention of educators and planners of programs and curricula to the importance of computerized strategy based on training in the teaching process, especially in mathematics; because of its impact on improving the level of students with learning disabilities (attention-deficit)in solving Math word problem.

- The computer-based training has the ability to make the learner active and effective during the acquisition of facts, skills and processes, in addition to the lack of Saudi Arabia studies on this topic; hence, there is a real need to investigate the effect of using computer software to acquire skills of solving Math word problems among students with learning disabilities in elementary schools.

- Parents are given an active role in the education of their children with learning disabilities (attention-deficit) inside the house with less effort and cost.

\subsection{Study Population and Sample}

The study population consisted of all students with learning disabilities in Mathematics in the city of Najran, enrolled in the program of learning disabilities in elementary schools for the academic year 2014/2015, numbered (70) students. The study sample consisted of (14) students with learning disabilities (attention-deficit)in Mathematics in the city of Najran, selected randomly from two schools, the control group is (7) students and the experimental group is (7) students as well.

\subsection{Instruments}

\subsubsection{First: Mathematics Achievement Test}

The authors of the current study developed a pre-and-post achievement test in Math word problems to measure the level of students with learning disabilities (attention-deficit) (the 
participants) in solving Math word problems. The number of paragraphs of the test is (20) Math word problems of multiple choice. The authors prepared the test considering test instructions, objectives, and how to answer it. They made sure that each paragraph must measure the four arithmetic skills (addition, subtraction, multiplication and division).

\section{Test Validity and Reliability}

A number of professors at the College of Education in Najran University, as well as supervisors and teachers who teach Mathematics for elementary school students reviewed and evaluated the test paragraphs and items. They expressed their opinion about the appropriateness of the paragraphs of the test for students with learning disabilities in Mathematics of the elementary stage, and necessary modifications have been made in line with the recommendations of the reviewers.

The test has been applied in its final draft to a sample of (10) students from non-study sample in order to verify reliability in a way of Re-test (Test-Retest) with seven-day interval, where Pearson correlation coefficient value was $(0.80)$ that considered an appropriate score for the purposes of the study.

\subsubsection{Secondly: Computer-based training strategy}

Training-based computerized strategy is the most common strategy, it is the first strategy used in teaching, so named because it helps the student review the scientific material and training, and it does not provide new information. Accordingly, it is the individual's ability to learn and train through computer programs that are mentally, skillfully, and scientifically suitable to the capabilities of the learner, so learner can feel confident during the learning process.

Computers offer a range of exercises and questions on Math word problems that have been explained by the teacher in order to enhance and enrich the student's skills, these exercises are offered individually so that the student can master the skill.

\subsection{Steps of Preparing the Strategy}

The following steps are followed to prepare this strategy:

1. Access to educational literature review to identify this training-based strategy, in terms of concept, its components, teaching methods, and how to apply it educationally, especially to Mathematics.

2. Access to literature review that have designed educational strategies in teaching of various courses, especially Mathematics, in order to determine the objectives of teaching, and how to follow the teaching methods.

3. Designing the computerized strategy through (Power Point) tech.

4. Setting a schedule for achieving the objectives, content of strategy based on the Mathematics curriculum at the elementary level. The strategy application took two weeks: one session a day. 
5. The strategy designed in collaboration with specialists, supervisors and teachers in Mathematics from the city of Najran.

6. Validity of the strategy content has been verified through presenting it to a group of evaluators and reviewers in Mathematics and Computer to give their feedback about the system and the content of the course related to solving Math wordproblems, the methods used in teaching, and the appropriateness of the strategy to the level students.

7. It was agreed with the teacher, who is responsible for teaching the experimental group, that the teaching process is monitored by the authors of the study themselves, for verifying that the teacher applied this strategy.

\subsection{Elements of the strategy}

1. Introduction to the subject of training: It is a reboot of the learner for the training process.

2. Thread the shape and type is included in the program: texts, charges and pictures.

3. Stop: the learner can stop during the learning process and the closure of the program then returns to the program to be able to end it.

4. The sentence response: the learner can recognize the result of what he learned through feedback in the program.

\subsection{Application}

The study was conducted in the second semester of the academic year 2014/2015, the teachers in learning disabilities was trained in Al-Markib Elementary School on how to use the training-based software, the teachers of mathematics at the school conducted a pre-test for all members of the study sample and then divided the students randomly into two groups: experimental group and control group, and began training the experimental group to skillfully solve the Math word problem through computerized strategy, with an average daily period for two weeks under the direct supervision of one of the authors. The control group had been trained by the math teacher in another school (Al-areysa Elementary School) with an average daily period for two weeks on the skills of solving word Math problem by the traditional method in the classroom.

At the end of the training, posttest of Math achievement applied to the study sample to measure their extent of achievement.

\subsection{Statistical Analysis}

After applying and conducting the present study, means and standard deviations of the total scores for the members of the study sample have been calculated. Mann-Whitney U Test was conducted to investigate statistically significant differences between the control group and the experimental group. 


\section{Results}

\subsection{Results of the First Question:}

To answer this question, Mann-Whitney U Test was conducted to investigate statistically significant differences between the control group and the experimental group on the pre-test of the skill of solving Math word problem as shown in Table (1).

\begin{tabular}{llcccrcc}
\hline Test & Group & No. & Mean & Sum & Mann-Whitney & Z-Value & Significance Level \\
\hline Pre- & Control & 7 & 6.79 & 47.50 & 19.500 & -.651 & 0.515 \\
& Experimental & 7 & 8.21 & 57.50 & & & \\
\hline
\end{tabular}

Table (1) shows that there are no statistically significant differences between the means of the control group and the experimental group for pre-test of the skill of solving verbal math problem; where the value of " $\mathrm{Z}$ " is (-.651) with statistical significant (.515) that is bigger than the level of statistical significance. $(a=0.05)$.

\subsection{Results of the Second Question}

To answer this question, Mann-Whitney U Test was conducted to investigate statistically significant differences between the control group and the experimental group on the post-test of the skill of solving Math word problem as shown in Table (2).

\begin{tabular}{clcccccc}
\hline Test & Group & No. & Mean & Sum & Mann-Whitney & Z-Value & Sig. Level \\
\hline \multirow{2}{*}{ Post- } & Control & 7 & 4.00 & 28.00 & .00001 & -3.162 & 0.002 \\
& Experimental & 7 & 11.00 & 77.00 & & & \\
\hline
\end{tabular}

Table (2) indicates that there are statistically significant differences between the means for members of the control group and the experimental group to the posttest for the skill of solving verbal math problem; where mean for members of the control group is (4.00), while mean for members of the experimental group is (11.00), and Z-value is (-3.162), statistically significant at (0.002) which is lower than the level of statistical significance $(a=0.05)$. Therefore, the results conclude that there is an effect of computerized strategy based on training on solving verbal math problem among students with learning disabilities.

\section{Discussion}

The results showed that there are statistically significant differences in the skill of solving the word Math problem in favor of the experimental group members who have studied using a computerized strategy based on training compared to members of the control group who studied in the traditional method, which means that the strategy used in this study has been effective in the development of skill of solving verbal math problem among the members of the experimental group. The current results are consistent with Al-Maliki (2008), who showed that there was an effect of utilizing the enriching activities by a computer program in 
the treatment of learning disabilities in Mathematics among a sample of third grade students with learning disabilities and the differences were in favor of the experimental group.

The study resulted that the computerized strategy is effective in making the student with learning disabilities learn actively and effectively during the acquisition of skills in educational situations full of excitement and competition, where educational programs take care of the capabilities of the learners, and enable them to learn according to their abilities. In addition, the computer software includes a collection of graphics, shapes, colors and music in educational units that provide entertainment and fun.

The authors of the current study confirm that the environment provided by the computer during the learning and teaching process in terms of communication and interaction among learners reflects positive attitudes among those students towards computer software as an educational method on the one hand, and towards courses that are taught on the other hand, which increases the motivation to learn, and thus increases their academic achievement in Mathematics, The attitudes of student with learning disabilities towards the use of computer software as an educational method are affected to a large extent with the efficiency and effectiveness of the entire computerized software. Therefore, the results given here are consistent with the study of Jeanine et al. (2012), conducted in the southwestern of America, which showed that there was an impact of the use of educational computer activities over the Internet upon improving academic achievement among students with learning disabilities in Mathematics.

The results of this study are in consistent with the results of studies that have pointed to the effectiveness of the computerized-learning method over the traditional learning method, although those studies have been conducted in other communities, and addressed various grades and measurement tools such as the study of Sobh and Ajlouni (2003), Martindale et al. (2005), Maliki (2008), Dinder (2008) and Kara (2009).

\section{Recommendations}

In the light of the results of the study, the authors recommend the following:

1. Conducting further studies about the impact of the use of computerized strategy based on training on developing the skill of solving problems, creative thinking and critical thinking among students with learning disabilities.

2. The educational institutions must provide educational computerized software for elementary school students in public schools.

3. Teachers of Mathematics at the elementary level should be made aware of the importance of applying the computer software in education.

\section{References}

Abu-Raiya, M. (1993). The impact of the use of play-based learning strategy implemented through the computer to acquire four computer skills among sixth grade students in private schools in Amman, unpublished Master Thesis. Amman: University of Jordan. 
Al-Maliki, A. (2008). The impact of using computerized enriching activities on the treatment of mathematical disabilities for the performance of third grade students with learning disabilities. Unpublished Master Thesis, Umm Al Qura University, Makkah, Saudi Arabia.

Al-sabagh, S. (2005). Survey on the impact of a training program for students in sixth grade elementary schools in Jordan on the development of numerical fluency on achievement in mathematics. Al-Basaer Journal, 9(1), 214-246.

Anil, K. (2002 ). A study of Indian University Distance Learners Academic - settle Concept, Study Habits and A attitudes Towards Distance Education in Relation to their Acadmic Performance - Implications for Learner Support and Instructional. Design Internet paper.

Bcal, C., \& Lee, H. (2008 ). Mathictors Motivation and Achievement as Predivtors fo High School Sudents, Guessing and Help -Seeking With Iinstouctional Software. Journal of Computer Assisted Learning, 24, 507-514. http://dx.doi.org/10.1111/j.13652729.2008.00288.x

Dinder, D. (2008). Exploring and Undertaking The Benefits of Tutoring Software on Urban Students Science Achievement Paper Presented at the Regional Educational. Research Association Conference, Hilton Head Islanel. USA.

Ersan, \& AbuZeina. (2003). The impact of a training program for strategies to solve math problem on developing the ability to solve mathematical problem and the achievement in mathematics among the elementary school students in Jordan. Journal of Muta University for Research and Studies, 20(7), 61-83.

Hall, L. K. (2002). Problem-Solving Strategies of Middle School Students: An Analysis of Gender Differences and Thinking in High - Achieving Students. UMI proQuest Digital Dissertations - 24 page preview. Retrieved from http://wwwlib.umi.com/dissertations

Jeanine L. W., Sally B., Corina, B., Candace, C., Lisa, M. R, \& Anthony, J. O. (2012). Online Instructional Materials for Students with Disabilities: Does it Work? International Journal of Education, 4(3), 12-30.

Kara, Y. (2009). The Effect of Tutorial Software on Student Acheivement, Misconceptions and Attitudes. Gazi University Journal, 29(3), 651-672.

Kirkpatrik, H., \& Cubar, L. (1998). Should we be worried? What the Research Says About Gender Differences in Access, vs. Attitudes, and Achievement with Computers. Educational Technology, 38(4), 56-58.

Marge, J. J. (2002). The Effect of Metacognitives Strategy Scaffolding on Student Achievement in Solving Complex math Word Problems. DAI-A62/07, p 2332.

Martindale, T., Pearson, C., Curda, L., \& Pilcher, J. (2005). The Effect of An online Instructional Application on Reading and Maths Stanardized Test Scores. Journal of

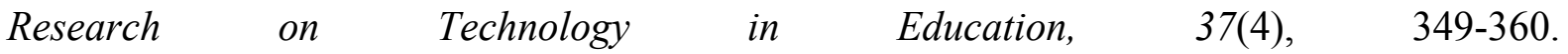
http://dx.doi.org/10.1080/15391523.2005.10782442 


\section{Macrothink}

International Research in Education

ISSN 2327-5499

2016, Vol. 4, No. 1

Nunes, D., \& Moreno, B. (2005). David Number Sense: Rethinking Arithmetic Instruction for Students with Mathematical Disabilities. The Journal of Special Education, 33(1), 33-50.

Ray, K. (2002). Student Attitudes Towards Electronic Information Resources Internet Innovations. Education and Teaching International, 11(1), 66-75.

Shashanni, L. (1995). Gender Differences in Mathematics Experience and Attitude Toward Computer. Educational Technology, 32-38.

Sobh, Y., \& Ajlouni, K. (2003). The impact of computer use in the teaching of mathematics for students in the secondary first grade on scientific achievement and attitudes towards computer, Journal of Studies, 30(1), 166-186.

\section{Copyright Disclaimer}

Copyright reserved by the authors.

This article is an open-access article distributed under the terms and conditions of the Creative Commons Attribution license (http://creativecommons.org/licenses/by/3.0/). 